\title{
Manajemen Pendidikan Pada Tadris Bahasa Indonesia STAIN Curup
}

\author{
Murni Yanto \\ Institut Agama Islam Negeri (IAIN) Curup \\ yantomurni.65@gmail.com \\ Ummul Khair \\ Institut Agama Islam Negeri (IAIN) Curup \\ ummulkhair@gmail.com
}

\begin{abstract}
This study aims to describe how education management in the Indonesian language structure STAIN Curup. This type of research is field research with a qualitative descriptive approach, the subjects of this study are the department heads, lecturers, study program staff and students. Data collection techniques through interviews, observation and documentation. Data analysis techniques used are data reduction, data presentation, and drawing conclusions. Data manipulation and techniques.

The results of this study indicate that: 1) leadership in the management of education in the Indonesian STAIN Curup tadris has been well implemented, 2) efforts to improve the management aspects of education in the Indonesian language system at STAIN Curup have been implemented is the autonomy of study programs in improving education quality. as an effort to seek input and increase enthusiasm to make a positive contribution to the study program. Transparency of one of the principles of good governance or good governance of the organization is needed to build a successful organization. Teamwork. collaboration is needed because cooperation will provide better work results, but cooperation is still low. Management of education in the Indonesian language class has had a positive impact on study programs.
\end{abstract}

Keywords: Education management, Aspects - Management aspects, Indonesian Language Management

Abstrak : Penelitian ini bertujuan untuk mendeskripsikan bagaimanakah manajemen pendidikan pada tadris bahasa Indonesia ST AIN Curup. Jenis penelitian ini adalab penelitian lapangan dengan pendekatan deskeriptif kualitatif, subyek penelitian ini adalab ketua jurusan, dosen,staf prodi dan mahasiswa. Teknik pengumpulan data melalui wawancara, observasi dan dokumentasi.Teknik analisa data yang digunakan reduksi data,penyajian data, dan penarikan kesimpulan.triangulasi data dan teknik.

Hasil penelitian ini menunjukkan bahwa :1) kepemimpinan dalam pengelolaan pendidikan pada tadris bahasa Indonesia STAIN Curup sudah terlaksana dengan baik, 2) upaya meningkatkan aspek-aspek. manajemen pendidikan pada tadris bahasa Indonesia di STAIN Curup sudab terlaksana adalah otonomi prodi dalam meningkatkan kualitas pendidikan.Partisipasi sebagai usaba untuk mencari masukan dan meningkatkean semangat untuk memberikan kontribusi positip bagi prodi. Trasparansi salah satu prinsip good governance atau tata kolala organisasi yang baik, sangat dibutubkan untuk membangun organisasi yang sukses.teamwork kerjasama tim diperlukan karena dengan kerjasama akan memberikan hasil kerja yang lebih baik, namun kerjasamanya masih rendah. Manajemen pendidikan pada tadris bahasa Indonesia memberikan dampak positif terhadap prodi.

Kata Kunci : Manajemen pendidikan, Aspek-aspek Manajemen, Tadris Bahasa

Indonesia

TADBIR : Jurnal Studi Manajemen Pendidikan vol. 3, no. 1, Mei 2019

IAIN Curup - Bengkulu | p-ISSN 2580-3581; e-ISSN 2580-5037 


\section{Pendahuluan}

Manajemen pendidikan merupakan strategi yang digunakan pemimpin dalam mengimplementasikan keahliannya pada suatu organisasi. Teknik dan strategi yang digunakan akan menentukan berhasil tidaknya organisasi dalam mewujudkan tujuannya.

Secara etimologis ( etimos=ilmu atau kajian ), ensiklopedia bebas wikipedia menjelaskan bahwa istilah menejemen berasal dari bahasa perancis kuno "management". Yang berarti seni melaksanakan dan mengatur.

Menurut Eddy Heryanto manajemen adalah suatu filosofi yang mengintergrasikan beberapa fokus utama, yaitu fokus pada pelanggaran, proses kerja, keuntungan, dan proses belajar yang berkelanjutan. Adapun beberapa manfaat yang dapat diperoleh dari penerapan manajemen pendidikan adalah : (1) mengurangi biaya operasi, (2) meningkatkan kepuasan pelanggan, (3) meningkatkan moral perusahaan, (4) membangun sebuah proses peningkatan, (5) menciptakan rekayasa ulang proses usaha, (6) membangun keunggulan kompetitif, (7) membangun dasar untuk mendapatkan pengakuan / sertifikasi. ${ }^{2}$

Menurut Miranda dan Tunggal, manajemen mutu berarti keseluruhan metode untuk mengatur mutu dalam suatu organisasi yang meliputi produk, jasa, kinerja, proses dan sumber daya manusia. ${ }^{3}$

Menajemen pendidikan telah banyak diulas oleh para ahli. Terry yang dikutip oleh Tripathi dan Reddy mendefinisikan menajemen sebagai "a process consisting of planning, organising and controlling, performed to determine and accomplish the objectives by the use of people and resources. ${ }^{4}$

Berdasarkan definisi diatas, maka dapat disimpulkan bahwa manajemen pendidikan secara keseluruhan merupakan kegiatan bersama dalam bidang pendidikan dilaksanakan dengan memanfaatkan semua fasilitas yang ada baik personil, material dan spiritual dalam mencapai tujuan pendidikan. Menajemen

1Suparlan, Manajemen Berbasis Sekolah Dari Teori Sampai dengan Praktik, (Jakarta: PT.Bumi Aksara,2013) h.41

2 Eddy heryanto, Manajemen Operasi, (Jakarta: Grasindo, 2008), h.398

${ }^{3}$ Miranda dan A.W. tunggal, Manajemen Logistik dan Supply Chain Management (Jakarta: Harvarindo, 2003), h. 157

4 P. C. Tripathi dan P.N. reddy, Principles of Management (New Delhi : Tata MCGraw-Hill Publishing Company Limited, 2008) h.2 
merupakan faktor utama terselenggaranya pendidikan dalam suatu lembaga. Manajemen merupakan seni untuk mengajak orang-orang dapat mengikuti peraturan yang dibuat dalam rangka mencapai tujuan organisasi.

Manajemen merupakan serangkaian kegiatan yang didesain untuk mncapai tujuan organisasi dengan menggunakan sumberdaya secara efisien dan efektif dilakukan dalam lingkungan senantiasa berubah dari waktu kewaktu.Manajemen pendidikan pada tadris bahasa Indonesia perlu ada otonomi kebebasan terkendali dalam menyampaikan ide dan gagasan kepada pimpinan, partisipasi atau peran serta prodi maupun partisipasi orang tua mahasiswa dalam bentuk kegiatan kampus. Kerjasama (Teamwork) belum memperlihatkan sebagai tim yang solid dilihat dari sikap yang ditunjukan pada tadris bahasa Indonesia STAIN Curup, yang mendahulukan kepentingan sendiri,dan komunikasi yang kurang kondusif di kampus, sikap yang demikian akan mengganggu untuk meningkatkan mutu.

Menurut Veithzal Riva'i dan Sylviana Murni Permasalahan pendidikan di era globalisasi sangat beragam mulai dari keterbatasan aksesbilitas dan daya tampung kerusakan sarana dan prasarana ruang kelas, kekurangan jumlah tenaga dosen, jumlah dan mutu buku yang belum memadai dari proses pembelajaran yang masih konvensional. ${ }^{5}$

Berdasarkan penjelasan tersebut, dapat disimpulkan bahwa pendidikan bukanlah upaya sederhana, melainkan suatu kegiatan dinamis dan penuh tantangan. Pendidikan selalu berubah seiring dengan perubahan zaman. Oleh karena itu menajemen senantiasa memerlukan upaya dan peningkatan kualitas serta tuntutan kehidupan masyarakat. Dengan penelitian ini diharapkan dapat memberikan informasi dan gambaran yang lebih mendalam dan komferehensif tentang manajemen pendidikan, Maka penelitian berusaha mengambil judul "Manajemen Pendidikan pada Tadris bahasa Indonesia di STAIN Curup".

\section{Fokus Penelitian}

Berdasarkan latar belakang masalah,Fokus penelitian ini adalah pada usaha mengungkapkan manajemen pendidikan dan upaya meningkatkan aspek aspek manajemen pendidikan.

${ }^{5}$ Veithzal Rivai dan Sylviana Murni, Education Management. (Jakarta: Rajawali Pers. 2009) hh. 30-32 


\section{Rumusan Masalah}

Berdasarkan latar belakang diatas, maka dapat dirumuskan masalah penelitian ini adalah :

1. Bagaimana kepemimpinan dalam proses pengelolaan pendidikan pada Tadris bahasa Indonesia di STAIN Curup ?

2. Bagaimana upaya meningkatkan aspek-aspek manajemen pendidikan pada Tadris bahasa Indonesia di STAIN Curup?

\section{Tujuan Penelitian}

Berdasarkan rumusan masalah dalam penelitian ini, tujuan penelitian ini ialah sebagai berikut :

1. Mendeskripsikan kepemimpinan dalam pengelolaan pendidikan bahasa Indonesia.

2. Mendeskripsikan manajemen pendidikan.

3. Mendeskripsikan aspek-aspek manajemen pendidikan.

\section{Landasan Teori}

\section{Pengertian Manajemen}

Dalam Kamus Inggris Indonesia Jhon M.Echols dan Hasan Sadily kata manage diartikan "mengurus, mengatur, melaksanakan, mengelola". Sementara itu dalam Kamus Besar Bahasa Indonesia manajemen diartikan sebagai proses penggunaan sumberdaya secara efektif untuk mencapai sasaran ${ }^{7}$. Sedangkan menurut Maisah manajemen adalah aktivitas yang prinsip untuk membuat suatu perbedaan dalam hal bagaimana organisasi lebih baik melayani orang yang telah dipengaruhi, sebagai bentuk tanggungjawab sosial yang memuaskan. ${ }^{8}$

Menurut Richard manajemen adalah the attaiment of organizational goals in an effective and efficent manner throungh planning, organizing, leading, and controlling organizational resource. Manajemen melalui perancanaan, organisasi, pembimbingan dan kontroling.' Menurut Robbins, Decenzo dan Coulter menjelaskan

\footnotetext{
${ }^{6}$ Jhon M. Echols dan Hassan Shadily, kamus Inggris Indonesia (Jakarta: Gramedia, 2010) h.372

7 Departemen Pendidikan dan Kebudayaan, Kamus Besar Bahasa Indonesia (Jakarta: Balai Pustaka, 1990) h 553

8 Maisah, Manajemen Pendidikan (Jakarta: Gaung Persada Press, 2013), h.1

${ }^{9}$ Richard L. Daft, New Era of Management (Canada: South-Western, 2010) h.5
} 
manajemen adalah "management is that process of getting things done, effectively and efficiently, with and throught other people". ${ }^{10}$

Menurut Cassidy dan Kreither manajemen adalah "the process of working with adn throught other to achieve organizational objective in a changing environment. ${ }^{11}$ Menurut Grifin manajemen didefinisikan sebagai berikut: Can be defined as a set of activies (including planning and decision making, organizing, leading and controlling) directed at an organizations resources (buman, financial, p-bysical, and information) with the aim of achieving organizational goals in an efficient and effective manner. ${ }^{12}$

\section{Manajemen Pendidikan}

.Menurut Burhanudin pengertian manajemen terkandung dua kegiatan, yaitu pikir (mind) dan kegiatan tindak laku (action). Kedua tindakan tersebut tampak fungsi-fungsi manajemen seperti, planning, organizing, directing, coordinating, controlling dan lain-lain. Sedangkan dilihat dari bahasa Inggris, kata manajemen merupakan kata kerja to manage yang berarti mengurus, mengatur, melaksanakan dan mengelola yang bersinonim dengan kata to hand yang berarti mengurus; to control yang berarti memeriksa; dan to guide yang berarti memimpin. ${ }^{13}$

Menurut Nizar Ali Manajemen sering diartikan sebagai ilmu, kiat dan profesi. Sebagai ilmu, manajemen dipandang sebagai suatu bidang pengetahuan yang secara sistematis berusaha memahami mengapa dan bagaimana orang bekerjasama ${ }^{14}$. Syahrizal Abbas Manajemen dalam makna organisasi dipahami dalam arti menyeluruh, yang meliputi berbagai dimensi diantarannya; perencanaan, pengorganisasian, pengarahan, pengawasan, dan pemanfaatan sumber daya organisasi dalam mencapai tujuan yang telah ditetapkan. ${ }^{15}$

\footnotetext{
10 Sthepen P. Robbins, Daviud A. Decenzo dan Mary Coulter, Fundamental of Management (United State of America: Peaerson, 2011), h.32

${ }^{11}$ Crassidy dan Kreather, Princples of Management (China: Western, 2011), h.5

12 Ricky W. Griffin, Management Principles and Practice (United State: Sounth-Western, 2013), h.5

13 Baharudin, Kepemimpinan Pendidikan Islam Antara Teori dan Praktik, (Yogyakarta: Ar-Ruzz, Media,2012), h. 111

14 Nizar Ali, Manajemen Pendidikan Islam : Ikhtiar Menata Pendidikan Islam, Jawa Barat: Pustaka Isfahan, 2009), h. 64

15 Syahrizal Abbas, Manajemen Perguruan Tinggi, (Jakarta: Prenada Media Group, 2008), h. 14-15
} 
Arifin Pendidikan adalah menumbuhkan personalitas serta menanam rasa tanggung jawab. Usaha kependidikan bagi manusia menyerupai makanan yang berfungsi memberikan vitamin bagi pertumbuhan manusia. ${ }^{16}$

A.I.Hartani Manajemen pendidikan dapat didefinisikan sebagai seni dan ilmu mengelola sumber daya pendidikan untuk mewujudkan suasana belajar dan proses pembelajaran agar peserta didik secara aktif mengembangkan potensi dirinya dalam rangka memiliki kekuatan spritual keagamaan, pengendalian diri, kepribadian, kecerdasan, akhlak mulia, serta keterampilan yang diperlukan dirinya, masyarakat, bangsa dan negara. ${ }^{17}$

Menurut Marno Substansi yang menjadi garapan manajemen pendidikan sebagai proses atau disebut juga fungsi manajemen adalah :

a. Perencanaan, menentukan tujuan serta cara-cara untuk mencapai tujuan.

b. Pengorganisasian, mengatur tugas Sumber Daya Manusia (SDM) untuk mencapai tujuan.

c. Penggerakan, mendorong karyawan agar bekerja keras untuk mencapai kinerja terbaik.

d. Pengawasan, mengukur hasil kerja serta tindakan supaya sesuai dengan hasil yang dimiliki. ${ }^{1}$

Menurut Hikmat proses pendidikan diperlukan dukungan managerial skill, seperti berkaitan dengan administrasi sekolah, misalnya pengelolaan waktu penerimaan calon siswa, surat-surat perkantoran, pengarsipan dan sebagainya. Oleh karena itu, manajemen pendidikan dapat diartikan sebagai rangkaian kegiatan yang menunjang tercapainya mekanisme dan tujuan pendidikan. ${ }^{19}$

\section{Fungsi Manajemen}

Fungsi manajemen saling berurutan dua terkait yang dibutuhkan:

(a)Perencanaan pengorganisasian, (b)Pengorganisasian,(c) Penggerakan,(d) Pengawasan.Kenneth N Wexley dan Gery A Yuke Kegiatan pengawasan dapat

\footnotetext{
16 Arifin, Ilmu Pendidikan Islam : Tinjauan Teoritis dan Praktis, (Jakarta: PT. Bumi Aksara, 2011), h. 7

17 A.l. Hartani, Manajemen Pendidikan, (Yogyakarta : Laksbang Pressindo, 2011), h.7

18 Marno, Manajemen dan Kepemimpinan Pendidikan Islam, (Bandung: PT. Refika Aditama, 2013), h.12

${ }^{19}$ Hikmat, Manajemen Pendidikan, (Bandung: CV. Pustaka Setia, 2009), h. 22
} 
di selenggarakan secara terus menerus, berkala, sewaktu-waktu pada saat sebelum, sedang atau setelah suatu kegiatan dilaksanakan. ${ }^{20}$

\section{Pengertian Mutu}

Menurut Goetsch dan Davis yang di kutip Tjiptono dan Diana memberikan batasan bahwa mutu merupakan suatu kondisi dinamis yang berhubungan dengan produk, jasa, manusia, proses, dan lingkungan memenuhi atau melebihi harapan. ${ }^{21}$

Menurut Ibrahim,Buddi mutu adalah suatu strategi dasar bisnis yang menghasilkan barang dan jasa yang memenuhi kebutuhan dan kepuasan konsumen internal dan eksternal secara eksplisit dan implisit. ${ }^{22}$

\section{Manajemen Mutu}

Menurut Gazpers manajemen mutu merupakan semua aktivitas dari fungsi manajemen seacra keseluruhan yang menentukan kebijakan mutu, tujuan dan tanggung jawab serta mengimplementasikannya melalui alat-alat manajemen mutu, seperti perencanaan mutu, pengendalian mutu, penjaminan mutu, dan peningkatan mutu. ${ }^{23}$

\section{Manajemen Mutu Terpadu}

${ }^{20}$ Kenneth N Wexley, dan Gary A. Yuki, Organization Behavior and Personil Psyikologi (New Jersey: Rycard D. Irwin, ind D Irwin Inc. 2006), h. 294

${ }^{21}$ Fandy Tjiptono dan Anastasia Diana, TQM: Total Quality Management (Yogyakarta: Andi, 2001), h.5

22 Buddy Ibrahim, Total Quality Management ; Panduan Untuk Menghadapi Persaiangn Global, (Jakarta: Djambatan, 2000), h.1

23.Vincent Gasperz, Total Quality Management (Jakarta: Gramedia, 2001), h. 122

24.Syarifuddin, Manajemen Mutu terpadu Dalam Pendidikan : Konsep, Strategi dan Aplikasi, (Jakarta: PT. Gramedia Widiasarana Indonesia, 2002), h. 36

25.Mawardi M. Amin, Manajemen Mutu Aplikasi dalam bidang Pendidikan, Yogyakarta: Media Akademi, 2016), h.42

26.Gary Yuki, leadership In Organization (New Jersey: Pearson Education, Inc. 2010), h. 26

27.P. T. Joseph, EQ and Leadership (New Delhi: Tata McGraw-Hill Publishing Company Limited, 2007), h. 25

28.Harold Kerzner, Project Management: A System Approach to Planning, Scheduling, and Controlling (Canada: Jhon Wiley \& Sons, Inc, 2009) h. 915 
Menurut Syafaruddin memberikan pengertian bahwa manajemen mutu tepadu dalam pendidikan adalah aplikasi konsep manajemen mutu yang disesuaikan dengan sifat dasar sekolah sebagai organisasi jasa kemanusiaan melalui pengembangan pembelajaran bermutu, agar melahirkan gagasan yang sesuai dengan harapan orang tua, masyarakat dan pelanggan pendidikan lainnya. ${ }^{24}$

Menurut Mawardi M. Amin menyatakan tujuan manajemen pendidikan yaitu meningkatkan produktivitas pendidikan yang dilihat dari efesiensi penyelenggaraan pendidikan dan efektifitas penyelenggaraan pendidikan. ${ }^{25}$

\section{Manajemen Kepemimpinan}

Kepemimpinan Gery Yuki secara umum dipahami sebagai :

"The process in influencing other to understand anf agree about what needs to be done how to do it, and the process of facilitatong individual and collective efforts to accomplish shared abjective". ${ }^{26}$

Kepemimpinan menurut Joseph sebagai "a process whereby one individuals influences a group of individuals to achieve a common goal in specific way"."

Kerzner menyatakan bahwa : "Quality leadership is an alternative that emphasizes by working on methods. In the type of management, every work, process is studied and constantly improved so that the final product or services not only meets by exceeds customer expectation".28

Menurut R.S Maaganarazan dan Arivalagar bahwa peran pemimpin adalah perbaikan mutu yang berkelanjutan meliputi : (1) mengidentifikasi fokus dan kebutuhan pelanggan, (2) merencanakan kerangka kerja mutu, (3) mendidik, melatih, memberdayakan dan mengembangkan karyawan, (4) mendapatkan keterlibatan dan komitmen karyawan, (5) perbaikan proses, (6) pengukuran dan 
penggunaan perangkat statisktik, dan (10) mengakui dan mengintegrasikan sistem penghargaan dengan praktek manajemen. ${ }^{29}$

\section{Aspek-Aspek Manajemen Pendidikan \\ Otonomi}

Menurut Gibson, et. Al. Otonomi adalah Setiap invidu membutuhkan hak untuk membuat keputusan dan tidak diawasi terus menerus. diungkapkan berikut :

Some people want jobs providing the right to make decisions; they want to operate without being closely supervised. A feeling autonomy could result from the freedom to do what the employee considers best in a particular situation. In jobs that are highly structured and controlled by management, it's difficult to create tasks that lead to a feeling of autonomy ${ }^{30}$

Dalam konseptual, Mullins menyatakan tenatng otonomi, yaitu "autonomy refer to the extent to which a job provides freedom, independence and discretion in planning the work and determining how to undertake it. Otonomi berarti kebenasan dan kemandirian dalam merencanakan dan menetapkan bagaimana pekerjaan dilakukan. ${ }^{31}$ Hellriegel dan Slocum memberikan batasan otonomi yaitu, "autonomy refer to the extent ti which the job provides empowerment and disrection to an employee in scheduling tasks and in determining procedures to be used in crying out those tasks" ${ }^{32}$. Pengertian lain tentang otonomi menurut George dan Jones, "autonomy is the degree to which a job allows an employee the freedom an independence to schulude work.

${ }^{29}$ R. S Maagarazan dan A.A. arivalagar, Total Quality Management (New Delhi: New Age International (P), Ltd. 2005) hh. 12-13

30.James L. Gibson, Jhon M. Ivancevich, James H. Donnelly, Jr dan Robert Konopaske Organizations : Behavior, Structure, Processes (New York: The McGraw-Hill Companies, Inc. 2012), h.178

${ }^{31}$ Laurie J. Millins, Management and Organiaational Behaviour (Essex: Pearson Education Limited, 2005), h. 716

32. Don Hellriegel dan Jhon W. Slocum, Jr. Organizational Behavior (Mason: Cengage Learning, 2011), h. 171

33.Jennifer M. George dan Gareth R. Jones, Understanding and Managing Organizational Behavior (New Jersey: Pearson Education, Inc. 2002) h. 187

34.Hilde Penneman, “Autonomy in Education: Review of The Country Report”, eds. Walter Berka, Jan De Groof dan Lilde Penneman (Cambridge: Kluwer Law International, 2000), h.

35.Wahyu Catur Adinugroho, I.N.N. Suryadiputra, Bambang Hero Saharjo dan Labueni Siboro, Panduan Pengendalian Kebakaran Hutan dan Lahan Gambut (Bogor: Wetlands Internasional, 2004), h. 132 
and decide how to carry it out. High otonomy generally contributes to high levels of intrinsic motivation". 33

Menurut Penneman Autonomy is the expression of the principle of freedom of education and the right to amintain and run private religous schools, and is apparent from the bodies entrusted with running schools ${ }^{34}$

\section{Partisipasi}

Partisipasi, menurut Adinugroho, e menjelaskan bahwa partisipasi sebagai keterlibatan mental dan emosional seseorang dalam suatu kelompok yang mendorongnya untuk bersedia memberikan sumbangan bagi tercapainya tujuan kelompok dan turut bertanggung jawab atas usaha-usaha yang dilakukan kelompoknya. $^{35}$

Menurut Dubri berikut:

To overcome resistance to change, allow people to paticipate in the changes that will affect them. In applying this concept, a manager can allow employees to set their own rules to increase compliance. A powerful participation technique is to encourage people who already favor the change to help in planning and implementation. These active supporters of the change will be even more strongly motivated to enlist the support of others. Participation is also useful because it gives the manager additional input into developing a careful plan for the change, including implementation. ${ }^{36}$

Robbins dan Coutler menjelaskan sebagai berikut:

Participation involves bringing those individuals directly affected by the proposed change into the decision-making process. Their participation allows these individuals to express their feelings, increase the quality of the process, and increase employee commitment to the final decision. $^{37}$

36 Andrew J. DuBrin, Essentials of Management(New Jersey: Pearson Education, Inc., 2012),h. 159

37.Stephen P. Robbins dan Mary Coulter, Management (New Jersey: Pearson Education, Inc., 2012), h. 159

38.John R. Schermerhorn, Jr., Exploring Management (New Jersey: John Wiley \& Sons, Inc., 2010), h. 240 
kepemimpinan partisipatif Schermerhorn menjelaskan "participative leader involves others in decision making; asks for and uses suggestions. ${ }^{38}$ Sementara menurut Kinicki dan Williams

Participating leader involves encouraging followers to solve problems on their own. Because it shares decision making, this leadership style encourages in performing tasks. ${ }^{39}$

. Menurut Conyers yang dikutip Solekhan, tiga alasan utama mengapa partisipasi masyarakat mempunyai arti sangat penting. Pertama, partisipasi masyarakat merupakan suatu alat guna memperoleh informasi mengenai kondisi, kebutuhan dan sifat masyarakat setempat yang tanpa kehadirannya proyek pembangunan serta proyek-proyek lainnya akan gagal. Kedua, masyarakat akan lebih mempercayai program atau proyek pembangunan jika dilibatkan dalam proses persiapan dan perencanaan. Ketiga, dalam perspektif demokrasi, partisipasi merupakan hak masyarakat untuk dapat terlibat dalam pembangunan. ${ }^{40}$

\section{Transparansi}

Menurut Richard W Oliver Transparansi terbentuk dari gabungan dua kata dari dua konsep yang berbeda, yaitu: trans yang bermakna gerakan, dan parent yang memilik Implikasinya bagi individu atau organisasi adalah bahwa transparansi membolehkan pihak lain untuk melihat kebenaran, tanpa mencoba untuk menyembunyikan atau mengaburkan makna, atau merubah fakta untuk dijadikan lebih baik. Transparansi juga dapat diartikan sebagai tingkat di mana hukum, regulasi, kesepakatan, dan praktik perdagangan internasional terbuka, jelas, terukur, dan dapat diverifikasi. ${ }^{41}$

\section{Teamwork}

Teamwork menurut Devine, Clayton, Philips, Dunford dan Malner yang dikutip oleh Aamodt, yaitu sebagai kumpulan dari tiga atau lebih individu yang berinteraksi secara intensif untuk menyediakan sebuah produk, perencanaan

\footnotetext{
39 Angelo Kinicki dan Brian Williams, Management: A Practical Introduction (New York: McGraw-Hill, 2012), h. 456

40 Moch Solekhan, Penyelenggaraan Pemerintahan Desa (Malang: Setara Press, 2012), h. 85

${ }^{41}$ Richard W. Oliver, What is transparency? (New York: McGraw-Hill, 2004), p.3
} 
keputusan, atau pelayanan organisasional. ${ }^{42}$. Menurut Snell dan Bohlander mendefinisikan kerja sama tim sebagai kelompok individu yang bekerja sama ke arah tujuan bersama, yang mana anggota kelompok memiliki keterampilan saling melengkapi, saling menguntungkan, dan kelompok memiliki keleluasaan di luar tugas yang telah dibentuk. ${ }^{43}$

Menurut Bateman dan Snell menyebutkan ada empat tipe tim. Pertama, tim proyekdan pengembangan (project and development teams). Tim ini bekerja pada proyek jangka panjang, umumnya lebih besar dari satu tahun. Kedua, tim paralel (paralell teams). Tim ini beroperasi secara terpisah dari struktur kerja yang biasa dari sebuah perusahaan.. Ketiga, tim manajemen (management teams). Tim ini mengkoordinasikan dan menyediakan arahan sub unit di bawah yurisdiksi dan kerja yang terintegrasi di antara sub unit. ${ }^{44}$

Selanjutnya timkerja yang akan mencapai keberhasilan adalah tim kerja yang padu atau kohesif. George dan Jones menjelaskan konsep kohesivitas tim, "team cohesiveness refer to the attractiveness of a group to its members." Konsep ini bermakna bahwa kohesivitas berkaitan dengan daya tarik sebuah kelompok bagi anggota-anggotanya. ${ }^{45}$ Kemudian Schermerhom, Hunt, dan Osborn menjelaskan "team cohesiveness is to degree to which members are attracted to a group and motivated to remain a part of it." kohesivitas dikemukakan Spoor dan Kelly yang dikutip oleh Slocum dan Hellriegel "team cohesiveness is the strength of members desire to remain in a term and their commitment to it." Kohesivitas adalah kekuatan kehendak anggota untuk bertahan dalam sebuah tim dan komitmennya terhadap tim. ${ }^{46}$

\section{Hasil Penelitian Dan Pembahasan}

42 Warren Bennis, James O’Toole, dan Daniel Goleman, Transparansi: Bagaimana Pemimpin Menciptakan Budaya Keterbukaan (Jakarta: Libri, 2009, p. 109

43 Michael G. Aamodt, Industrial/Organizational Pscychology (United States; Thomson Wadsworth, 2007), h. 451

${ }^{44}$ Scott Snell dan George Bohlander, Human Resource Management (Canada; Thomson, 2007), h. 157

45 Jennifer M. George and Gareth . Jones, Organizational Behavior (New Jersey: Pearson Educaion,Inc., 2002), h. 307

46 John W. Slocum, Jr and Don Hellriegel, Fundamental of Organizational Behavior (Ohio: South-Western, 2007), h. 126 


\section{Kepemimpinan}

Dalam konsep kepemimpinan yang di kembangkan adalah dengan menerapkan nilai-nilai kekeluargaan. Dalam hal ini mempimpin sebuah organisasi diibaratkan sama dengan memimpin keluarga yang dapat ditujukan dengan hal saling mencintai dan menghormati, keterbukaan, kebersamaan dalam menghadapi suka dan duka, dan keadilan.

Kepemimpinan yang diimplementasikan adalah kepemimpinan melayani. kepemimpinan yang demikian diharapkan dapat membangun kebersamaan dan kerjasama tim yang kuat. Semangat melayani ini juga terus ditanamkan ke staf dan dosen agar dapat memberikan pelayanan terbaik kepada para mahasiswa dan juga masyarakat.

Kepemimpinan organisasi merupakan faktor yang sangat fundamental dan menentukan keberhasilan sebuah organisasi. Upaya meningkatkan aspek-aspek manajemen pendidikan:

\section{Otonomi Prodi}

Otonomi prodi yang luas menjadi salah satu ciri implementasi Manajemen pendidikan, sehingga diharapkan prodi dapat leluasa dalam mengambil kebijakan untuk meningkatkan kualitas pendidikannya.Pada prodi tadris bahasa Indonesia.Informasi yang digali terutama dari prodi diperoleh suatu gambaran bahwa prodi memiliki otonomi penuh dalam pengelolaan pendidikannya. Otonomi prodi yang luas menjadi salah satu ciri manajemen pendidikan.

\section{Partisipasi}

Partisipasi adalah salah satu ciri penting dalam penerapan manajemen pendidikan.Partisipasi diperlukan sebagai usaha untuk mencari masukan dan meningkatkan semangat untuk memberikan kontribusi positif bagi prodi. Prodi juga menyadari akan pentingnya partisipasi sebagai salah satu pilar dalam implementasi manajemen pendidikan. Partisipasi prodi dibutuhkan baik dari staf, dosen, mahasiswa maupun orang tua mahasiswa.Untuk mengakomodasi hal tersebut, maka prodi mengembangkan pula kepemim pinan partisipatif, sehingga banyak melibatkan warga prodi dalam pengambilan kebijakan dan keputusan menyangkut kepentingan prodi. 
Partisipasi suatu usaha untuk mencari masukan dan memberikan semangat untuk kontrabusi yang positif bagi prodi.

\section{Transparansi}

Transparansi adalah salah satu prinsip good governance atau tata kelola organisasi yang baik, sehingga modal yang sangat dibutuhkan untuk membangun organisasi yang sukses. Organisasi prodi juga membutuhkan transparasi pengelolaannya, sehingga dapat dikontrol oleh semua pihak yang berkepentingan.Prodi selama ini juga menerapkan prinsip transparansi dalam pengelolaan prodi. Oleh karena itu, prodi melakukan kontrol baik secara internal maupun eksternal. Transparansi adalah filar yang dibutuhkan dalam mendukung kesuksesan manajemen pendidikan.

\section{Teamwork}

Teamwork warga prodi dituntut solid dalam bekerja sehingga mengemban tugas dengan semangat kebersamaan.

Kerjasama diperlukan karena dengan kerjasama akan memberikan hasil kerja yang lebih baik. Semua warga prodi dituntut solid dalam bekerja sehingga dapat mengemban setiap tugas-tugas dengan semangat kebersamaan.

\section{Pembahasan Hasil Penelitian}

\section{Kepemimpinan}

Setiap keterampilan penting yang harus dimiliki untuk menerapkan kepemimpinan melayani yaitu memahami kebutuhan personal bawahan, menangani konflik, menjadi pelayan sumber daya organisasi, dan menjadi pendengar yang efektif. Terkait dengan kepemimpinan prodi, maka prodi sudah menunjukkan kemampuan dalam membangun hubungan secara interpersonal dengan bawahan dan juga ditunjukkan dengan kemampuannya membangun suasana kekeluargaan di prodi :

Pertama, hati yang melayani. Kepemimpinan yang melayani dimuali dari dalam diri sendiri. Kepemimpinan menuntut suatu transformasi dari dalam hati dan perubahan karakter. Kepemimpinan sejati dimulai dari dalam dan kemudian bergerak keluar untuk melayani mereka yang dipimpinnya. Ada sejumlah ciri dan nilai yang muncul dari seorang pemimpin yang memiliki hati yang melayani, yaitu : (1) Tujuan paling utama seorang pemimpin adalah melayani kepentingan 
mereka yang dipimpinnya, (2) Seorang pemimpin sejati justru memiliki kerinduan untuk membangun dan mengembangkan mereka yang dipimpinnya, (3) Keberhasilan seorang pemimpin sangat tergantung dari kemampuannya untuk membangun orang-orang disekitarnya. (4) seorang pemimpin yang memiliki hati yang melayani adalah akuntabilitas.

Kedua, prodi yang melayani. Seorang pemimpin sejati tidak cukup hanya memiliki hati atau karakter semata, tetapi juga harus memiliki serangkaian metoda kepemimpinan agar dapat menjadi pemimpin efektif.

Ketiga, tangan yang melayani. Pemimpin sejati bukan sekedar memperlihatkan karakter dan integritas, serta memiliki kemampuan dalam metoda kepemimpinan, tetapi harus menunjukkan perilaku maupun kebiasaan seorang pemimpin.

\section{Otonomi Prodi}

Pada penelitian ini menemukan bahwa Tadris Bahasa Indonesia memiliki perbedaan besar dibandingkan prodi lain khususnya dalam hal otonomi pengelolaan prodi. Prodi Tadris Bahasa Indonesia diberikan otonomi yang luas dalam rekrutmen mahasiswa, pengelolaan anggaran, pegelolaan sumber daya manusia, dan pengelolaan prodi secara menyeluruh. Otonomi-otonomi seperti itu harus dimiliki oleh prodi, sehingga sangat menguntungkan bagi prodi untuk mengembangkan prodinya menjadi lebih baik.

otonom prodi dalam mengelola prodi diberikan otonomi rekrutmen mahasiswa, pengelolaan anggaran prodi, pengelolaan sumber daya manusia, dan kemahasiswaan,dengan saling mencintai, keterbukaan, ketaatan terhadap perintah, kebersamaan dan keadilan.

\section{Partisipasi}

Partisipasi merupakan faktor penting yang harus ada demi keberhasilan dalam pengelolaan pendidikan atau prodi. Menurut Rivai dan Mulyadi bahwa pengambilan keputusan merupakan proses utama dalam mengelola organisasi. ${ }^{47}$ Proses pengambilan keputusan pada dasarnya merupakan penetapan suatu alternatif pemecahan masalah yang terbaik dari sejumlah alternatif yang ada.

47 Veithzal Rivai dan Deddy Mulyadi, Kepemimpinan dan Perilaku Organisasi (Jakarta: Rajawali Press, 2009), hh. 129-130 
Pengambilan keputusan merupakan kunci bagi kegiatan yang dilakukan oleh pemimpin, dimana serangkaian kegiatan dipilih dan pilihan ini mencerminkan alternatif tindakan yang terbaik bagi penyelesaian masalah.

Menurut Adinugroho, et al. bahwa partisipasi sebagai keterlibatan mental dan emosional seseorang dalam suatu kelompok keterlibatan mental dan emosional seseorang dalam kelompok yang mendorongnya untuk bersedia memberikan sumbangan bagi terciptanya tujuan kelompok dan turut bertanggung jawab atas usaha-usaha yang dilakukan kelompoknya. ${ }^{48}$

\section{Transparansi}

Menurut Bennis, O’Toole, dan Goleman menyatakan bahwa definisi transparan sebenarnya cukup sederhana, yaitu mampu dilihat secara tembus pandang, tanpa muslihat ataupun menutup-nutupi; terbuka, jujur, terus terang. ${ }^{49}$

\section{Teamwork}

Menurut, Devine et al, yang dikutip Aamodt, menjelaskan bahwa teamwork sebagai kumpulan dari tiga atau lebih individu yang berinteraksi secara intensif untuk menyediakan sebuah produk, perencanaan, keputusan atau pelayanan organisasional. ${ }^{50}$ Kemudian Snell dan Bohlander mendefinisikan kerjasama tim sebagai kelompok individu yang bekerja sama ke arah tujuan bersama, yang mana anggota kelompok memiliki keterampilan saling melengkapi, saling menguntungkan dan kelompok memiliki keleluasaan di luar tugas yang telah dibentuk. $^{51}$

Menurut Malcolm McGreevy, teamwork umumnya digunakan untuk perbaikan pada empat area kunci, yaitu: (1) produktivitas; teamwork dapat membuat tenaga kerja lebih efektif dan efisien dan dapat meningkatkan produktivitas, (2) meningkatkan kualitas dan memperkuat inovasi produk.

\footnotetext{
48 Wahyu Catur Adinugroho, I. N. N. Suryadiputra, Bambang Hero Saharjo dan Labuei Siboro, Panduan Pengendalian Kebakaran Hutan dan Lahan Gambut) (Bogor: Wetlands Internasional, 2004), h. 132

49 Warren Bennis, James O’Toole, dan Daniel Goleman, Transparansi: Bagaimana Pemimpin Menciptakan Budaya Keterbukaan (Jakarta: Libri, 2009), h. 109

50 Michael G. Aamodi, Industrial/ Organizational Pscychology (United States: Thomson Wadsworth, 2007), h. 451

51 Scott Snell dan George Bohlander, Human Resource Management (Canada: Thomson, 2007), h. 157
} 
Penetapan kualitas dan kepuasan pelanggan pada agenda yang paling atas di kebanyakan organisasi telah menjadikan dorongan yang kuat bagi inisiatif tim kerja; (3) kemajuan teknologi. Kemajuan dalam teknologi dalam semua bidang telah membuka kemungkinan baru untuk meningkatkan jangkauan pelayanan, dan (4) memberi motivasi. Dalam konteks prodi, maka teamwork dimaksudkan untuk meningkatkan produktivitas kerja, meningkatkan kualitas kerja dan inovasi serta memberikan motivasi bagi warga prodi. ${ }^{52}$ Teamwork orang yang bekerja dan mewujudkan tujuan bersama saling membantu.

\section{Simpulan}

Berdasarkan hasil analisis dan pembahasan, maka kesimpulan adalah :

1. Manajemen kepemimpinan mengimplementasikan konsep kepemimpinan melayani. keteladanan dan menjalankan kepemimpinan yang menganut nilai-nilai Islami, yaitu saling mencintai, keterbukaan, kebersamaam dan keadilan.

2. Aspek-aspek manajemen pendidikanTadris bahasa Indonesia sebagai berikut :

a. Otonomi rekrutmen mahasiswa, yaitu memulia dari teknik penyelenggaraan penentuan kelulusan, penetapan prosedur pendaftaran mahasiswa dan sosialisasi penerimaan mahasiswa.

b. Partisipasi atau peran serta warga prodi dalam memberikan ide atau gagasan terhadap kegiatan-kegiatan prodi.

c. Prodi melaksanakan perinsip transparansi dalam mengelola prodi. Implementasi prinsip transparansi terutama ditunjukkan dalam penerimaan mahasiswa baru secara online, transparansi dalam pembiayaan pendidikan

d. Teamwork berjalan dengan baik dan solid. Teamwork dapat dilihat dari sikap kooperatif yang ditunjukkan oleh warga prodi, sikap warga mementingkan kebersamaan dengan berkembangnya sikap

52 Malcolm McGreevy, “Team Working: part I-an Evaluation Of Current Thinking,'Journal of Industrial and Commercial Training, Vol.38, No. 5, 2006, h. 260 


\section{Saran}

tidak egois dan pokus pada tujuan prodi serta komunikasi cukup kondusif.

Berdasarkan simpulan hasil penelitian, maka saran-sarannya:

1. Prodi dalam menerapkan manajemen pendidikan harus lebih terkonsep, perencanaan tertulis dalam pelaksanaannya dapat lebih terarah.

2. Prodi perlu menyelenggarakan pelatihan terutama kepada dosen dan staf untuk memberikan pemahaman yang komprehensif tentang pelaksanaan manajemen pendidikan.

\section{Daftar Pustaka}

Aamodt, Michael G. Industrial/Organizational Pscychology. United States : Thomson Wadsworth, 2007.

Ali Imron, Proses Manajemen Tingkat Satuan Pendidikan, Malang : Bumi Aksara,2013

Baharuddin, Kepemimpinan Pendidikan Islam : Antara Teori dan Praktik, Yogyakarta: Ar-Ruzz Media.2012

Buddy Ibrahim.Total Quality Management : Panduan Untuk Menghadapi Persaingan Global, Jakarta : Djambatan.2000

Creswell, Jhon W. Educational Research: Planning, Conducting and Evaluating Quantitative and Qualitative Research. Boston: Pearson Education Inc., 2012.

Daft, Richard L. Management. USA: South-Western, 2003.

DuBrin, Andrew J. Essentials of Management. Mason: Sout-Western, 2012.

Fandy Tjiptono dan Anastasia Diana,TQM: Total Quality Managemant Yogyakarta:Andi.2001

Gasperz, Vincent. Total Quality Management. Jakarta: Gramedia, 2001.

George, James L., Jhon M. Ivancevich, James H. Donnelly, Jr. dan Robert Konopaske. Organizations: Behavior, Structure, Processes. New York: The McGraw-Hill Companies, Inc., 2012.

Griffin, Ricky W. Management. Mason: South-Western Cengage Learning, 2011. Hellriegel, Don danJhon W. Slocum, Jr. Organizational Behavior. Mason: Cengage Learning, 2011. 
Herjanto, Eddy. ManajemenOperasi. Jakarta: Grasindo, 2008.

Ibrahim, Budi. TQM, Total Quality Management: Panduanuntuk Menghadapi Persaingan Global. Jakarta: Djambatan, 2000.

Joseph, P. T. EQ and Leadership.New Delhi: Tata McGraw-Hill Publishing Company Limited, 2007.

Kenneth N. Wexley, dan Gary A Yukl. Organizational Behavior and Personnel Psychology. New Jersy: Richard D. Irwin Inc, 2006.

Kerzner, Harold. Project Management: A Systems Approach to Planning, Scheduling, and Controlling. Canada: Jhon Wiley \& Sons, Inc., 2009.

Kinicki, Angelo dan Brian Williams Management: A Practical Introduction. New York: McGraw-Hill, 2012.

M.Sakthivel Murugan,Management Principles and Practices.New Delhi: New Age Internasional Limited Publishers. 2005

Mawardi M.Amin, Manajemen Mutu Aplikasi dalam bidang Pendidikan, Yogyakarta : Media Akademi.2016

McMillan, James H. dan Sally Schumacer.Research in Education: Evidence-Based Inquiry. Boston: Pearson Education, Inc., 2006.

Miranda dan A. W. Tunggal.ManajemenLogistikedan Supply Chain Management. Jakarta: Harvarindo, 2003.

Moh.Nazir, Metode Penelitian, Bogor: Ghalia Indonesia.2011

Mullins, Laurie J. Management and OrganisationalBehaviour. Essex: Prentice Hall, 2005.

Mulyasa, E. ManajemenBerbasis Sekolah. Jakarta: Rosdakarya, 2004.

Murphy, J. Restructuring Through School-Based Management. Edited by T. Townsend. London: Routledge, 1997.

Nizar Ali, Manajemen Pendidikan Islam: Ikbtiar Menata Kelembambagaan Pendidikan Islam, Jawa Barat : Pustaka Isfahan.2009

Nugroho, Rian. KebijakanPublik: Formulasi, Implementasi, danEvaluasi. Jakarta: Gramedia, 2004.

Penneman, Hilde. "Autonomy in Education: Review of the Country Reports." In Walter Berka, Jan De Groof and LildePenneman, eds. Autonomy in Education, Cambridge: Kluwer Law International, 2000. 
Robbins, Stephen P. dan Mary Coulter.Management.New Jersey:Person Education, Inc., 2012.

Schermerhorn, Jr., Jhon R. Exploring Management. New Jersey: Jhon Wiley \& Sons, Inc., 2010.

Schermerhorn, Jr., Jhon R. James G. Hunt and Richard N. Osborn. Organizational Behavior. Ohio: South-Western, 2007.

Snell, Scott dan George Bohlander.Human Resource Management.CanadaL Thomson, 2007.

Solekhan, Moch. PenyelenggaraanPemerintahanDesa. Malang: Setara Press, 2012.

Suparlan, Manajemen Berbasis Sekolah Dari Teori Sampai dengan Praktik, Jakarta : PT.Bumi Aksara.2013.

Syafarudidin.Manajemen MutuTerpadu dalam Pendidikan: Konsep, Strategi, dan Aplikasi. Jakarta: PT. GramediaWidiasarana Indonesia, 2002.

Syahrizal Abbas, Manajemen Perguruan Tinggi,( Jakarta : Prenada Media Group.2008.

T.Hani Handoko,Management, Yogyakarta: BPFE, 2000.

Thomas S. Bateman dan Scott A. Snell.Management: Leading \& Collaborating in a Competitive World. New York: McGraw-Hill, 2007.

Tjiptono, FrandydanAnastasioa Diana. TQM: Total Quality Management. Yogyakarta: Andi, 2001.

Tripathi, P. C. dan P. N. Reddy.Principles of Management.New Delhi: Tata McGraw-Hill Publishing Company Limited, 2008.

Undang-undang nomor 20 tahun 2003 tentang Sisitem Pendidikan Nasional Pasal 1, ayat 1.

Undang-undang nomor 20 tahun 2003 tentang Sisitem Pendidikan Nasional Pasal 15.

Usman, Husaini, 2008.Manajemen Teori, Praktek, dan Riset Pendidikan, Edisi Kedua, Jakarta : PT. Bumi Aksara.2008.

Yukl, Gary. Leadership in Organization. New Jersey: Pearson Education, Inc., 2010. 
96 | TADBIR : Jurnal Studi Manajemen Pendidikan, Vol. 3, No. 1, Mei 2019

This page belongs to the TADBIR : Jurnal Studi Manajemen Pendidikan

TADBIR : Jurnal Studi Manajemen Pendidikan vol. 3 , no. 1, Mei 2019

IAIN Curup - Bengkulu | p-ISSN 2580-3581; e-ISSN 2580-5037 